\title{
Design of Class E Resonant Rectifiers and Diode Evaluation for VHF Power Conversion
}

\author{
Juan A. Santiago-González ${ }^{*}$, Khalil M. Elbaggari ${ }^{*}$, Khurram K. Afridi ${ }^{* *}$ and David J. Perreault ${ }^{*}$ \\ *Dept. of Electrical Engineering and Computer Science \\ Massachusetts Institute of Technology \\ Cambridge, MA, USA \\ juansant@mit.edu,kmyke@mit.edu and djperrea@mit.edu \\ ** Dept. of Electrical, Computer, and Energy Engineering \\ University of Colorado at Boulder \\ Boulder, CO, USA \\ khurram.afridi@colorado.edu
}

\begin{abstract}
Resonant rectifiers have important applications in very-high-frequency (VHF) power conversion systems, including dc-de converters, wireless power transfer systems, and energy recovery circuits for radio-frequency systems. In many of these applications, it is desirable for the rectifier to appear as a resistor at its ac input port. However, for a given dc output voltage, the input impedance of a resonant rectifier varies in magnitude and phase as output power changes. This paper presents a design methodology for Class $E$ rectifiers that maintain near-resistive input impedance along with the experimental demonstration of this approach. Resonant rectifiers operating at $30 \mathrm{MHz}$ over 10:1 and 2:1 power ranges are used to validate the design methodology and identify its limits. Furthermore, a number of Si Schottky diodes are experimentally evaluated for VHF rectification and categorized based on performance.
\end{abstract}

\section{INTRODUCTION}

Resonant rectifiers have important applications in power conversion systems operating at frequencies above $10 \mathrm{MHz}$. Applications for these circuits include very-high-frequency dc-dc converters [1-8], wireless power transfer systems $[4,9,10]$, and energy recovery circuits for radio-frequency systems $[5,6]$. In many of these applications, it is desirable for the rectifier to appear as a resistive load at its ac input port. For example, in some very-high-frequency dc-dc converters, proper operation of the inverter portion of the circuit can depend upon maintaining resistive (but possibly variable) loading in the rectifier stage. In still other applications it is desired to have an input impedance that is resistive and approximately constant across operating conditions $[5,6]$; this can be achieved by combining a set of resonant rectifiers having variable resistive input impedances with a resistance compression network [5,7-10]. In all these systems, however, it is desirable to maintain resistive input impedance of the rectifier as the operating power varies.

Resonant rectifiers have been explored in a variety of contexts [9-21]. The traditional design of a class $\mathrm{E}$ rectifier, or shunt-loaded resonant rectifier, utilizes a (large) choke

Sponsored by an MIT-SkTech Strategic Development Project, the MIT Center for Integrated Circuits and Systems and the MIT/MTL GaN Energy Initiative.

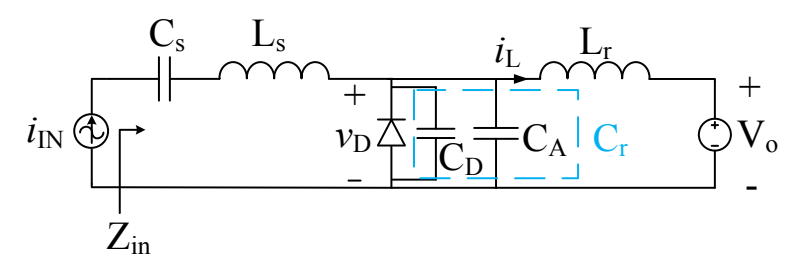

Figure 1. Class $\mathrm{E}$ resonant rectifier driven by a current source. In this model, intrinsic capacitance $C_{D}$ plus external capacitance $C_{A}$ form a total capacitance $\mathrm{C}_{\mathrm{r}}$.

inductor at its output and does not provide near-resistive input impedance [3,11]. This paper introduces a design method for realizing class $\mathrm{E}$ rectifiers that provide near-resistive input impedance over a wide range of output power levels. This methodology was initially explored in [22]. Experimental validation of the proposed method is also provided along with its limitations. The selection of a diode is also critical in very high frequency (VHF) designs (30-300 $\mathrm{MHz}$ ), as the performance of many diodes degrades as switching frequency increases [12,23]. This phenomenon is also explored in this paper through evaluation of different commercial diodes.

Section II presents a design methodology for class E rectifiers that yields resistive ac input impedance characteristics over a wide operating power range. Section III presents supporting experimental results. Resonant rectifiers operating at $30 \mathrm{MHz}$ over 10:1 and 2:1 power ranges are developed and used to validate and identify the limits of the design methodology. Section IV explores the suitability of a variety of Si Schottky diodes for use in VHF resonant rectifiers. A number of commercially-available Si Schottky diodes are experimentally evaluated for VHF rectification and categorized based on performance. Finally, section V concludes the paper.

\section{Class E Rectifier Design Methodology}

Here we present a methodology for designing class $\mathrm{E}$ rectifiers that maintain resistive input impedance over a wide 
power range. The design of the class $\mathrm{E}$ rectifier begins with its specification of frequency $f(=\omega / 2 \pi)$, dc output voltage $V_{o}$ and rated output power $P_{o, \max }$. These specifications can be used in conjunction with Figs. 2-4 to identify component values that minimize the worst case input impedance phase for a given power range ratio $\left(\mathrm{P}_{\mathrm{o}, \max }: \mathrm{P}_{\mathrm{o}, \min }\right)$ as determined by the numerical investigation in [22]. The detailed derivation and explanation of how Figs. 2-4 are generated can also be found in [22].

Figure 2 shows the absolute value of the maximum input impedance phase vs. normalized capacitance $C_{n}$ for four different power range ratios $(2: 1,5: 1,10: 1$ and 20:1). The capacitance is normalized as follows:

$$
C_{n}=C_{r} \frac{2 \pi f V_{o}^{2}}{P_{o, \max }}
$$

where $P_{o, \max }$ is the maximum (rated) output power. The plot shows that to minimize the worst case input impedance phase over the specified operating power range, the capacitance should be selected as a minimum within other design constraints (such as device voltage rating, etc.). The value of capacitance obtained with this methodology includes the intrinsic capacitance of the diode, any stray capacitance and any additional external capacitance if needed. Hence, $\mathrm{C}_{\mathrm{r}}$ cannot be chosen to be smaller than the intrinsic capacitance of the diode. A value of capacitance above this level should be chosen based on the acceptable value of maximum input impedance phase.

The next step is to select an appropriate diode. The required voltage rating of the diode for the selected normalized capacitance can be determined from Fig. 3. Figure 3 plots the normalized diode peak reverse voltage vs. normalized capacitance. The voltage is normalized to the dc output voltage:

$$
V_{D, n}=\frac{V_{D, p k}}{V_{o}}
$$

where $V_{D, p k}$ is the diode peak voltage. The normalized reverse voltage blocking capability of the diode must be greater than what is indicated by Fig. 3. The voltage stress on the diode reduces as capacitance increases. Hence, Fig. 3 gives a minimum achievable capacitance value for a given diode peak reverse voltage rating. Once the diode is selected, one can check Fig. 2 to ensure that the maximum input phase of the rectifier is within acceptable limits. If not, one might want to change the diode for one with a higher voltage rating and/or lower capacitance.

The next step is to select an appropriate value of $\mathrm{L}_{\mathrm{r}}$. Figure 4 shows a plot of normalized inductance vs. normalized capacitance. The inductance is normalized as follows:

$$
L_{n}=L_{r} \frac{2 \pi f P_{o, \max }}{V_{o}^{2}} .
$$

From this chart one determines the appropriate value of inductance $L_{r}$ that will yield the most resistive input impedance across the specified operating power range for the selected capacitance.

Finally, the input $\mathrm{L}_{\mathrm{s}}-\mathrm{C}_{\mathrm{s}}$ filter is chosen so that its resonant frequency is equal to the drive frequency $f$ and it provides an adequate $Q$ to achieve the desired spectral purity of the

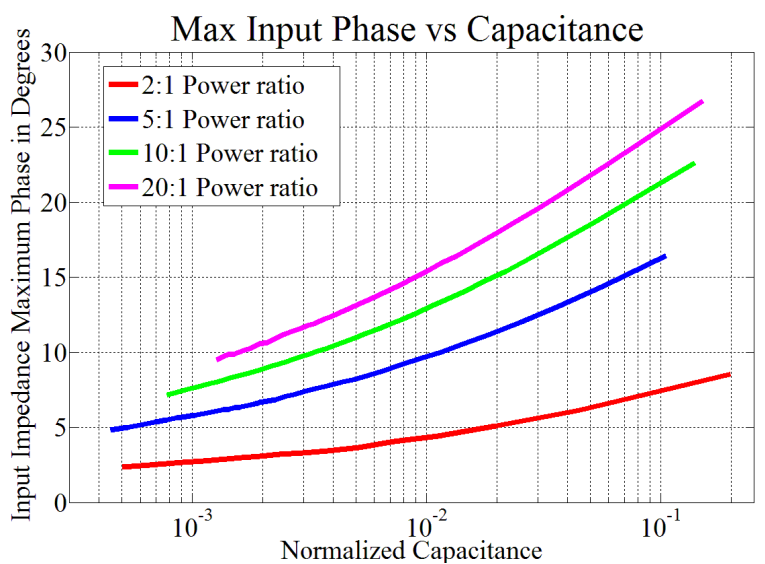

Figure 2. Worst-case phase angle magnitude across the specified operating conditions vs. normalized capacitance for different power range ratios $\left(\mathrm{P}_{\mathrm{o}, \max }: \mathrm{P}_{\mathrm{o}, \min }\right)$.

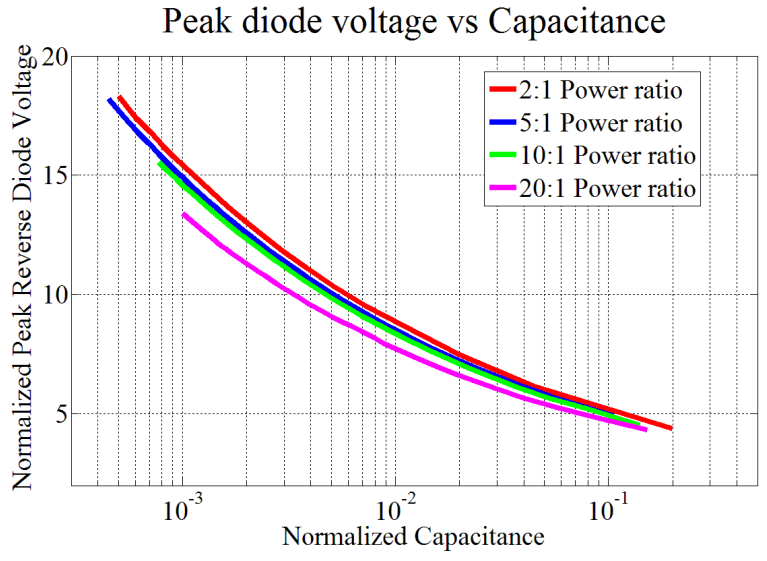

Figure 3. Maximum normalized peak diode voltage vs. normalized capacitance for different power range ratios $\left(\mathrm{P}_{\mathrm{o}, \max }: \mathrm{P}_{\mathrm{o}, \min }\right)$.

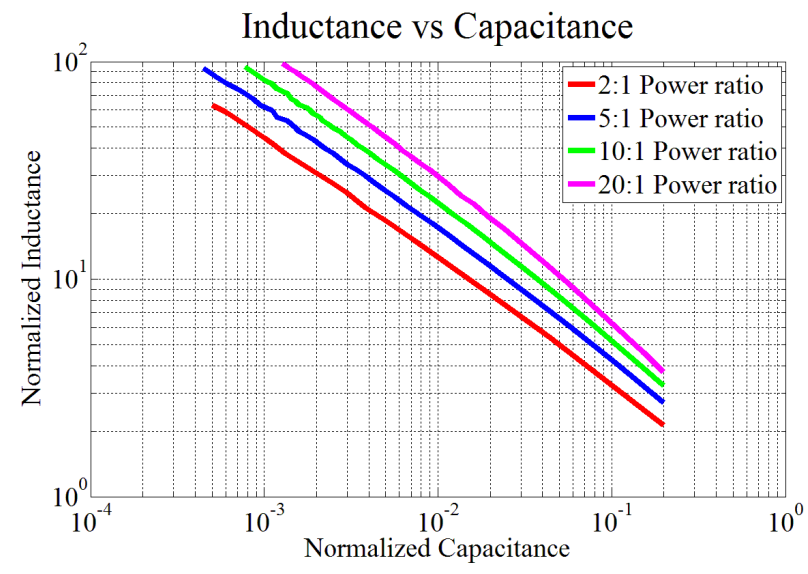

Figure 4. Normalized inductance vs. normalized capacitance for different power ranges ratios $\left(\mathrm{P}_{\mathrm{o}, \max }: \mathrm{P}_{\mathrm{o}, \min }\right)$. 
rectifier input waveforms for the application in question. We can quantify the relationship as:

$$
\sqrt{\frac{L_{s}}{C_{s}}}=Q R_{\text {min }},
$$

where $L_{s}$ and $C_{s}$ are the input filter inductance and capacitance, respectively, $Q$ is the quality factor of the filter and $R_{\min }$ is the minimum value (at rated power) of the magnitude of rectifier input impedance $Z_{\text {in }}$. The following section presents experimental results using this methodology that validates the approach.

\section{EXPERIMENTAL VALIDATION}

Figure 5 shows one of the boards used in testing the rectifier performance. The rectifier is driven by a power amplifier (AR 150A100B) with a sinusoidal input from a signal generator (BK Precision 4087). The load of the rectifier is a zener bank that consists of 10 SMBJ5349B diodes connected in parallel and mounted to a heat sink. The output $\mathrm{dc}$ voltage and current are measured with multimeters (Agilent $\mathrm{U} 3606 \mathrm{~A}$ and $34401 \mathrm{~A}$ ), the rectifier voltage is measured with a (10x, $500 \mathrm{MHz}$ ) oscilloscope probe model TPP0050, and the rectifier input current is measured with the TCP0030A current probe (120 MHz). The oscilloscope used was the MSO4054B.

The biggest assumption in the design methodology is that the diode capacitance is constant with voltage (i.e., that the capacitance is linear). Two rectifiers were built to demonstrate the effectiveness of the design methodology. The first rectifier is a high-capacitance design where the additional (highly linear) capacitance $\mathrm{C}_{\mathrm{A}}$ is much bigger than the diode capacitance $C_{D}$ (where $C_{D}$ is approximated as the diode capacitance when biased at the output voltage as read from the datasheet's $\mathrm{C}-\mathrm{V}$ curve). This is done by allowing a design having relatively high input impedance phase (big deviation from resistive behavior) as per the curves of Fig. 2. The second rectifier was designed with $\mathrm{C}_{\mathrm{A}}$ on the same order as $C_{D}$. The first (high capacitance) rectifier was designed for a maximum phase to be around $30^{\circ}$ with a predicted peak diode voltage of $38 \mathrm{~V}$ over a $10: 1$ power range ratio. The circuit parameters are shown in Table I. The second (low capacitance) rectifier was designed for a predicted maximum phase shift of $10^{\circ}$ and a predicted peak diode voltage of $53 \mathrm{~V}$ over a 2:1 power range. Table II shows the circuit parameters of this low capacitance rectifier. Both rectifiers used the SS16 diode from Vishay.

The effective rectifier impedance is defined as the complex ratio of rectifier fundamental input voltage $v_{I N}$ to rectifier fundamental input current $i_{I N}$. The input impedance at a given power level is found by measuring the input voltage and current, extracting the fundamental frequency component of each signal through Fourier analysis in MATLAB, and taking the ratio of the two. (It is noted that the rectifier input voltage and the diode voltage ideally have the same fundamental, as the input tank is tuned on resonance. In some cases input impedance is estimated using measurements of diode fundamental voltage as the "input" voltage. This is done so we can see the peak diode voltage which is more useful than the input voltage). The ratio of the fundamental voltage

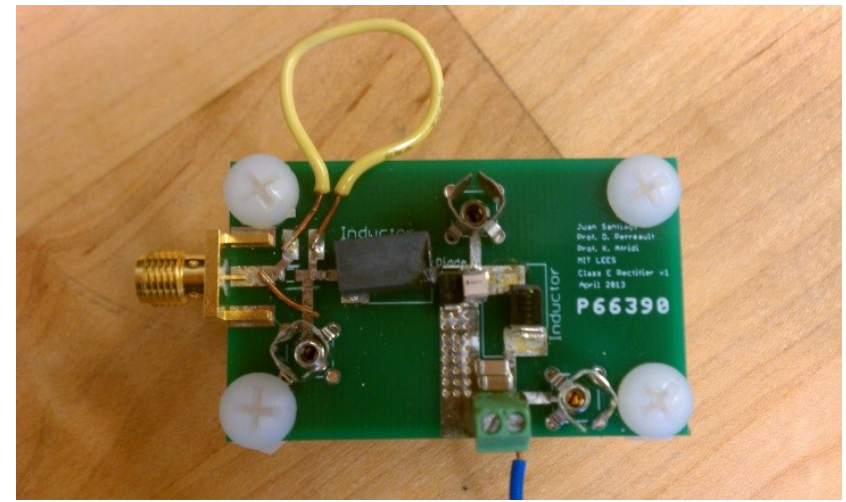

Figure 5. Class E resonant rectifier rated for $15 \mathrm{~W}, 12 \mathrm{~V}$ output voltage and $30 \mathrm{MHz}$ switching frequency.

TABLE I. RECTIFIER CIRCUIT PARAMETERS FOR A DESIGN WITH RELATIVELY LARGE EXTERNAL CAPACITANCE ACROSS THE DIODE, OPTIMIZED FOR A 10:1 POWER RATIO.

\begin{tabular}{|c|c|c|}
\hline Parameter & $\begin{array}{c}\text { Design } \\
\text { Value }\end{array}$ & Circuit Implementation \\
\hline$P_{O}$ & $1.5-15 \mathrm{~W}$ & $1.5-15 \mathrm{~W}$ \\
\hline$V_{O}$ & $12 \mathrm{~V}$ & $\begin{array}{c}12-13 \mathrm{~V} \\
10 \mathrm{x} \text { SMJ5349B in } \\
\text { parallel }\end{array}$ \\
\hline$f$ & $30 \mathrm{MHz}$ & $30 \mathrm{MHz}$ \\
\hline$L_{S}$ & $307 \mathrm{nH}$ & $\begin{array}{c}307 \mathrm{nH} \\
\text { Coilcraft MAXI Spring }\end{array}$ \\
\hline$C_{S}$ & $91 \mathrm{pF}$ & $\begin{array}{c}91 \mathrm{pF}, 250 \mathrm{~V} \\
\text { ATC } 600 \mathrm{~S} 910 \mathrm{JT} 250 \mathrm{XT}\end{array}$ \\
\hline$L_{r}$ & $51 \mathrm{nH}$ & $\begin{array}{c}48 \mathrm{nH} \\
\text { Coilcraft MIDI Spring }\end{array}$ \\
\hline$C_{r}$ & $477 \mathrm{pF}$ & $\begin{array}{c}477 \mathrm{pF} \\
47 \mathrm{pF} \\
\text { Vishay SS16 }\end{array}$ \\
\hline$C_{D}$ & $47 \mathrm{pF}$ & $\begin{array}{c}100 \mathrm{pF}, 500 \mathrm{~V} \\
\text { ATC100B101JW } \\
330 \mathrm{pF}, 200 \mathrm{~V} \\
\text { ATC100B331JW }\end{array}$ \\
\hline$C_{A}$ & $430 \mathrm{pF}$ & $\begin{array}{c}2 \times 10 \mu \mathrm{F}, 50 \mathrm{~V}, \mathrm{TDK} \\
\text { C3225X7S1H106K250AB }\end{array}$ \\
\hline$C_{\text {OUT }}$ & $20 \mu \mathrm{F}$ &
\end{tabular}

amplitude to fundamental current amplitude is the magnitude of the impedance and the phase shift between the fundamental voltage and current signals is the impedance phase. In order to measure the phase accurately, it is important that the oscilloscope and its probes are calibrated and deskewed with good precision before each test. The delay between the probes needs to be adjusted (deskewed) to get an accurate phase measurement.

A circuit that aids in calibrating the oscilloscope was developed. The circuit was built on a similar board to the rectifier and consists of the same input LC filter of the 
TABLE II. RECTIFIER CIRCUIT PARAMETERS FOR A DESIGN WITH RELATIVELY SMALL EXTERNAL CAPACITANCE ACROSS THE DIODE, OPTIMIZED FOR A 2:1 POWER RANGE RATIO.

\begin{tabular}{|c|c|c|}
\hline Parameter & $\begin{array}{c}\text { Design } \\
\text { Value }\end{array}$ & Circuit Implementation \\
\hline$P_{O}$ & $6-12 \mathrm{~W}$ & $6-13 \mathrm{~W}$ \\
\hline$V_{O}$ & $12 \mathrm{~V}$ & $\begin{array}{c}12-12.7 \mathrm{~V} \\
10 \mathrm{xMBJ} 5349 \mathrm{~B} \text { in } \\
\text { parallel }\end{array}$ \\
\hline$f$ & $30 \mathrm{MHz}$ & $30 \mathrm{MHz}$ \\
\hline$L_{S}$ & $307 \mathrm{nH}$ & $\begin{array}{c}307 \mathrm{nH} \\
\text { Coilcraft MAXI Spring }\end{array}$ \\
\hline$C_{S}$ & $91 \mathrm{pF}$ & $\begin{array}{c}91 \mathrm{pF}, 250 \mathrm{~V} \\
\text { ATC } 600 \mathrm{~S} 910 \mathrm{JT} 250 \mathrm{XT}\end{array}$ \\
\hline$L_{r}$ & $133 \mathrm{nH}$ & $\begin{array}{c}130 \mathrm{nH} \\
\text { Coilcraft MAXI Spring }\end{array}$ \\
\hline$C_{r}$ & $88.4 \mathrm{pF}$ & $\begin{array}{c}89 \mathrm{pF} \\
47 \mathrm{pF} \\
\text { Vishay SS16 }\end{array}$ \\
\hline$C_{D}$ & $47 \mathrm{pF}$ & $\begin{array}{c}12 \mathrm{pF}, 500 \mathrm{~V} \\
\text { ATC100B120JT } \\
30 \mathrm{pF}, 500 \mathrm{~V} \\
\text { ATC100B300JT }\end{array}$ \\
\hline$C_{A}$ & $41.4 \mathrm{pF}$ & $\begin{array}{c}2 \times 10 \mu \mathrm{F}, 50 \mathrm{~V}, \mathrm{TDK} \\
\mathrm{C} 3225 \mathrm{X} 7 \mathrm{~S} 1 \mathrm{H} 106 \mathrm{~K} 250 \mathrm{AB}\end{array}$ \\
\hline$C_{\text {OUT }}$ & $20 \mu \mathrm{F}$ \\
\hline
\end{tabular}

rectifier (including the current probe) with a $50 \Omega \mathrm{rf}$ load. The circuit was tuned appropriately at the fundamental switching frequency so that at $30 \mathrm{MHz}$ the impedance seen at the input is a pure $50 \Omega$ resistive load. Figure 6 shows the input voltage and current of the calibration circuit. The calibration circuit is connected to the power amplifier and driven by a small amount of power and the delay on the current and voltage probes is adjusted so that the signals overlap and have zero phase shift between them. This sets the scope to the zero phase or resistive impedance: any variation of the phase will be caused by the rectifier circuit.

Figures 7 and 8 show the experimental results for the high-capacitance rectifier. Simulation results are also plotted; the simulation is ideal, including only a linear device capacitance of $47 \mathrm{pF}$, and does not include parasitic inductances, diode forward drop, output voltage increase with power due to zener diode impedance or other non-idealities. The plot shows that the maximum impedance phase is $30^{\circ}$, which confirms our expected value from the design plots in section II (predicted values of $30^{\circ}$ for operation from $1.5 \mathrm{~W}$ to $15 \mathrm{~W}$ ). Figure 9 shows the measured diode voltage and input current at full power. The measured peak diode voltage is 42 $\mathrm{V}$, which is very close to the value of $38 \mathrm{~V}$ predicted using Fig. 3 for this design. It is suspected that this small deviation is due to the increase in output voltage (above $12 \mathrm{~V}$ ) owing to the nonzero impedance of the zener bank load. A simulation that includes the output voltage increase to $13 \mathrm{~V}$ at full power shows the peak diode voltage is increased to $40 \mathrm{~V}$. This confirms our expected value of peak diode voltage based on the design plots from section II.

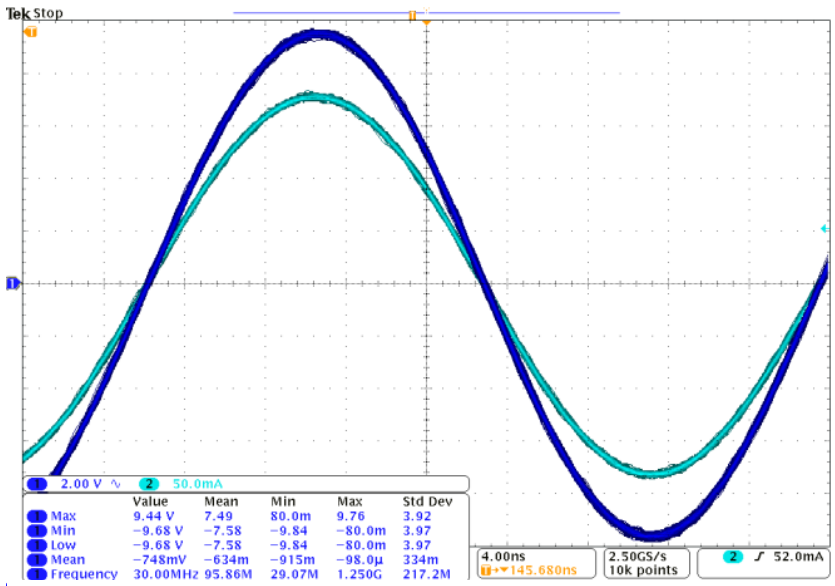

Figure 6. Calibration circuit voltage (dark blue) and current (light blue) waveforms. The oscilloscope is calibrated so that the waveforms are in phase with a $50 \Omega$ load at $30 \mathrm{MHz}$.

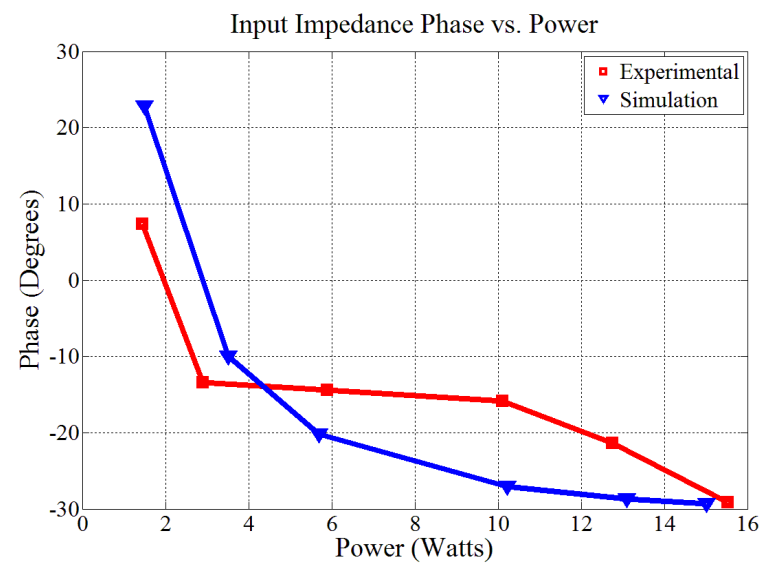

Figure 7. Input impedance phase vs. output power for the high-capacitance rectifier circuit described in Table I. The red curve is the measured experimental data and the blue curve is the simulation data. The maximum absolute phase magnitude over the specified power range is $30^{\circ}$.

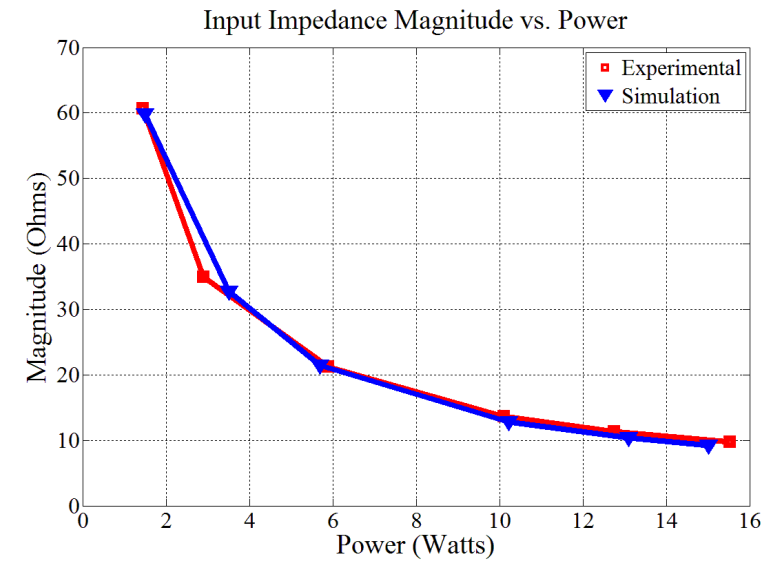

Figure 8. Input impedance magnitude vs. output power for the highcapacitance rectifier circuit described in Table I. The red curve is the measured experimental data and the blue curve is the simulation data.

Figures 10 and 11 show the experimental results for the low-capacitance design of Table II. Once again, experimental and simulation data is plotted. While there is a reasonable match between simulation and experiment, the match is not nearly as good as in the high-capacitance case (where diode capacitance nonlinearity is not important). In this case, the measured impedance amplitude exceeds that expected by 


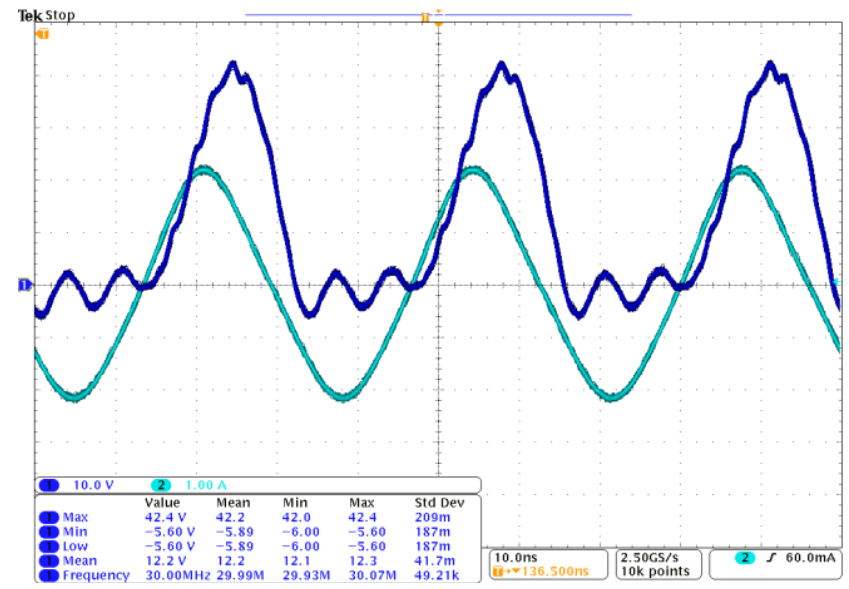

Figure. 9. Diode voltage (dark blue) and input current (light blue) at full power, $15.53 \mathrm{~W}$ for the circuit of Fig. 5 and values in table I. The peak diode voltage is $42 \mathrm{~V}$.

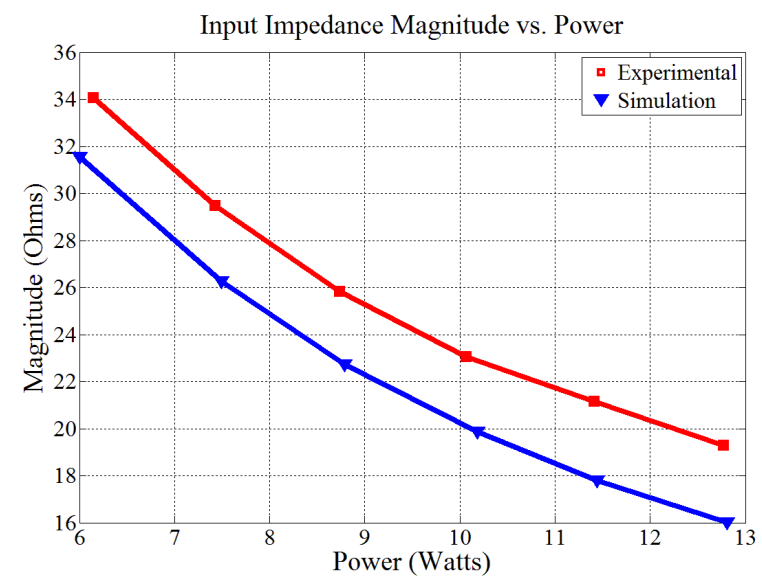

Figure 11. Input impedance magnitude vs. output power for the low-capacitance rectifier circuit described in Table II. The red curve is the measured experimental data and the blue curve is the simulation data.

approximately 6-22\% over the operating range and the maximum phase shift exceeds $15^{\circ}$ at low power levels, while simulation predicts a worst-case deviation of only $10^{\circ}$ from resistive. This shows one of the limitations of the design methodology: the voltage variation of the diode junction capacitance can place a limit on the accuracy of the design methodology.

The design methodology assumes a constant diode capacitance, but this assumption is valid when the external capacitance is considerably higher than the assumed constant value of the diode capacitance or when the actual diode capacitance is nearly constant with voltage. In the diode tested (Vishay's SS16), the capacitance varies between $210 \mathrm{pF}$ and $19 \mathrm{pF}$ between $0.1 \mathrm{~V}$ and $60 \mathrm{~V}$. As the capacitance varies over the switching cycle, the diode voltage waveform varies from that of a system having a constant diode capacitance. A simulation is prepared with $\mathrm{C}_{\mathrm{A}}=85.9 \mathrm{pF}$ (additional shunt capacitance), $\mathrm{Lr}=89.13 \mathrm{nH}$, a constant diode capacitance $\mathrm{C}_{\mathrm{D}}$ of $47 \mathrm{pF}$ and a variable $\mathrm{C}_{\mathrm{D}}$ of $222.95 /\left(1+\mathrm{v}_{\mathrm{D}} / 0.9511\right)^{0.5987} \mathrm{pF}$. The variable capacitance model was derived from a curve fitting of the C-V plot on the datasheet of an SS16 diode, while the constant value was taken from the same plot at the average diode voltage. Figure 12 shows the peak diode voltage

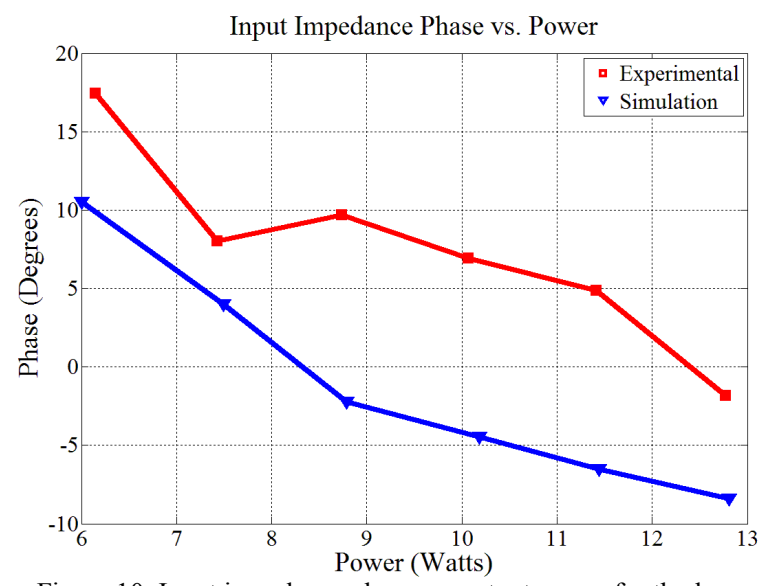

Figure 10. Input impedance phase vs. output power for the lowcapacitance rectifier circuit described in Table II. The red curve is the measured experimental data and the blue curve is the simulation data.

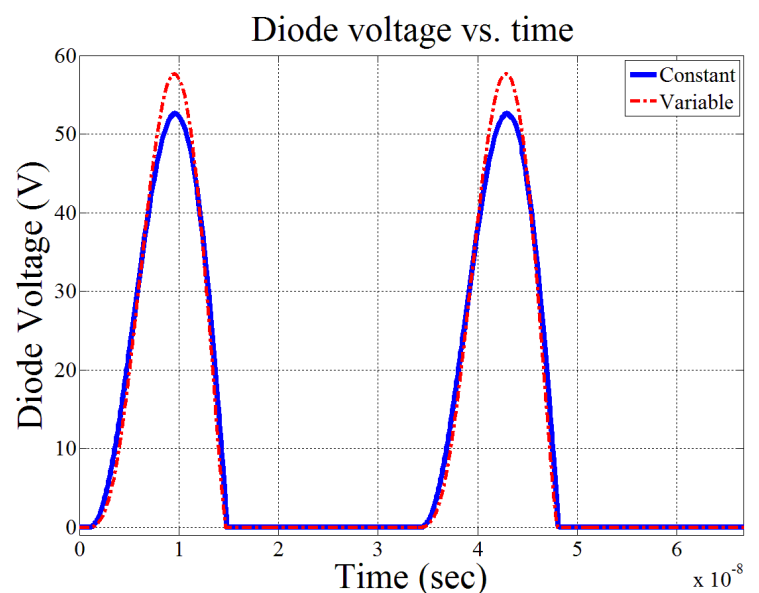

Figure 12. Simulation results: Diode voltage vs. time for a diode constant capacitance and for a variable diode capacitance. For the variable-capacitance case, the range of the diode capacitance is 210 to

$19 \mathrm{pF}$ according to instantaneous voltage, while the capacitance for constant-capacitance case is $47 \mathrm{pF}$. The external capacitance is $86 \mathrm{pF}$. At higher instantaneous voltage, the variable capacitance is lower and thus the diode voltage peaks higher.

simulation results for the two diode capacitance models at the same output power $(18 \mathrm{~W})$ and output voltage level $(12 \mathrm{~V})$. It is clear that the behavior of the circuit changes depending on the capacitance model used.

Moreover, as power varies, the effective value of the diode capacitance varies, changing the input impedance from what would be predicted by the design curves (Figs. 2-4). For example, consider the diode in the rectifier discussed above. If the external capacitance is comparable in magnitude to the diode capacitance at a dc output voltage of $12 \mathrm{~V}$, the capacitance on the cathode node is dominated by the external capacitance when the instantaneous diode voltage is high. As power goes down, the peak voltage on the diode decreases and the node capacitance increases and is dominated by the diode nonlinear capacitance. This makes it difficult to select an exact equivalent capacitance (to represent the variable diode capacitance), as the correct value varies with input power. The effect can also be seen in Fig. 13. The peak diode voltage at full power was predicted to be $53 \mathrm{~V}$ which is acceptable for the SS16 (a $60 \mathrm{~V}$ diode), but the experimental value is $60.6 \mathrm{~V}$. The simulation with increased output zener voltage of $12.7 \mathrm{~V}$ 


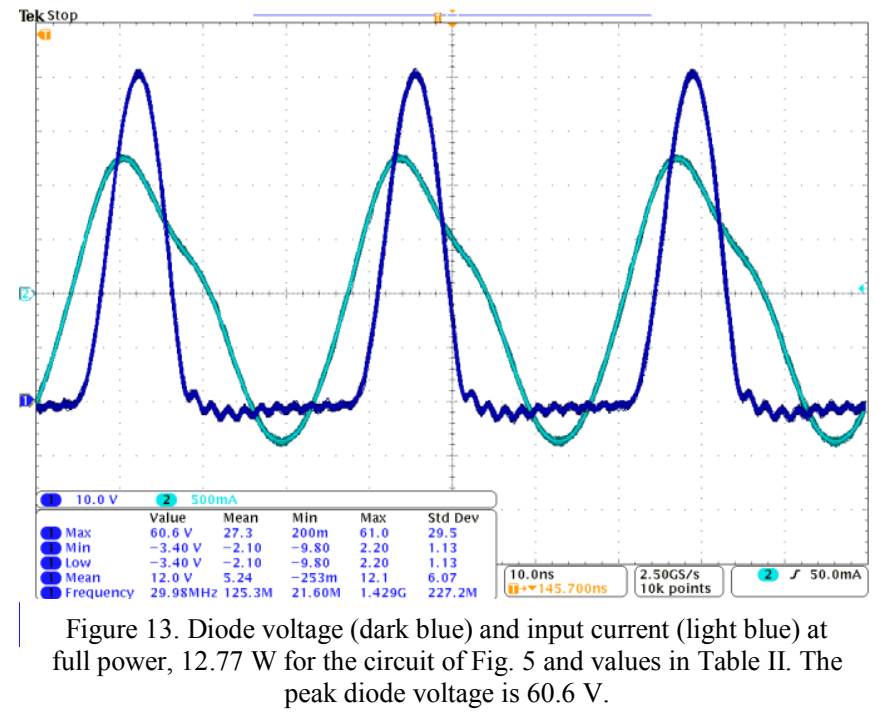

yielded $54.4 \mathrm{~V}$ of peak diode voltage, an increase of $2.64 \%$ which is still less than the $14.3 \%$ increase present in the experimental data. This increase in peak diode stress is also due to lower node capacitance at high voltages. These phenomena are not present in the high capacitance design seen in previously, as the capacitance was dominated by the linear external capacitance.

In summary, all the predictions by the design methodology are accurate for the case where the total capacitance across the diode (including diode capacitance) does not vary much with voltage (e.g., owing to using substantial external linear capacitance or having a diode with only small capacitance variation). However, accuracy degrades for the case where the effective capacitance across the diode varies substantially with voltage. This presents a limitation in the design method, but iterations on a design starting from design predictions with the proposed method could yield better results.

\section{Diode Performance Evaluatiojn}

Some Si Schottky diodes have been found to perform very poorly for resonant rectification at VHF frequencies, exhibiting much higher temperature rises and lower current limits than might be expected from datasheet information $[12,22]$. To study this issue systematically, fourteen commercially-available Si Schottky diodes were tested at 30 $\mathrm{MHz}$ in class $\mathrm{E}$ rectifiers. Each rectifier was designed and built using the methodology described above, based on the capacitance of the tested diode. The three best-performing diodes were also tested at $50 \mathrm{MHz}$.

The performance of each diode was assessed by measuring the power dissipation in the diode operating in a class E rectifier. Since determining power through voltage and current measurements is very challenging at VHF, a thermal characterization method was used to simplify the power measurements. First, the diodes were characterized by determining the relationship between their surface temperature and the power dissipated in them using accurate $\mathrm{dc}$ measurements. The rectifier board is populated exactly as if used in resonant rectification so that the heat dissipation

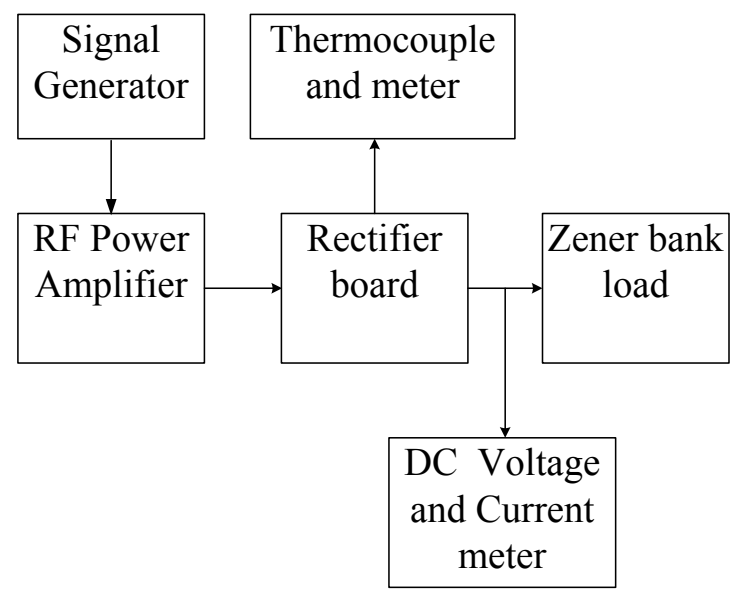

Figure 14. Block diagram of the experimental setup for the diode performance evaluation.

capability of the system is the same whether the diode carries dc or rf current. The temperature is measured on the board trace (on copper, not on soldermask) close to the anode of the diode using a K-type thermocouple. Because the anode is grounded, the thermocouple will add no significant capacitance to the circuit. Figure 14 shows a block diagram of the experimental setup. The signal generator, rf power amplifier and dc meters are the same used in the previous section. The thermometer is a Digi-Sense Scanning Thermometer. This thermal characterization of the diode was then used to determine the power dissipated in the diode with the rectifier operating at VHF frequencies by measuring diode temperature rise under $r f$ operation.

The diodes selected for testing are shown in Table III. The diodes can be sorted into seven groups having the same pair of nominal rated peak reverse voltage and nominal rated maximum average forward current (MAFC): $\{40 \mathrm{~V}, 1 \mathrm{~A}\},\{40$ $\mathrm{V}, 2 \mathrm{~A}\},\{60 \mathrm{~V}, 1 \mathrm{~A}\},\{60 \mathrm{~V}, 2 \mathrm{~A}\},\{60 \mathrm{~V}, 3 \mathrm{~A}\},\{100 \mathrm{~V}, 1$ $\mathrm{A}\}$ and $\{100 \mathrm{~V}, 2 \mathrm{~A}\}$. Thus, seven rectifiers were built to test each group. Each rectifier was designed for a dc output voltage $V_{0}$ equal to $20 \%$ of its rated diode peak voltage, maximum output power $P_{o, \max }$ equal to $V_{0}$ times the MAFC of the diode, a 5:1 power range ratio, a maximum voltage stress on the diode of $80 \%$ its peak rated voltage, and an operating frequency $f$ of $30 \mathrm{MHz}$. Using these design rules, reading from Figs. 2-4 we obtain $C_{n}=0.3$ and $L_{n}=2.0$. The expected maximum phase magnitude is $22^{\circ}$. The value of $C_{D}$ is different for each diode, so we select the value of $\mathrm{C}_{\mathrm{A}}$ as appropriate to obtain a constant value of $\mathrm{C}_{\mathrm{r}}$ for a given rectifier. Also, some of the $2 \mathrm{~A}$ and $3 \mathrm{~A}$ diodes were also tested for operation at lower currents of $1 \mathrm{~A}$ and $2 \mathrm{~A}$, respectively. For this reason, 21 tests were performed for the 14 diodes listed in Table III. Table IV shows the component values of the seven different rectifiers designed to test the seven groups of diodes.

During testing, the temperature on the diode was measured in steps of $20 \%$ of full diode average current starting from 0 up to $100 \%$. After a step increase in the current, we would wait 5 minutes for the temperature to settle and the system to reach thermal equilibrium before taking a temperature measurement. There were two conditions for which the experiment would be stopped before reaching $100 \%$ 
TABLE III. DIODES TESTED FOR USE IN CLASS E RECTIFIERS AT VHF.

\begin{tabular}{|c|c|c|c|}
\hline Diode & $\begin{array}{c}\text { Rated } \\
\text { Peak } \\
\text { Voltage } \\
\text { Vrev,pk }\end{array}$ & $\begin{array}{c}\text { Maximum } \\
\text { Average } \\
\text { Forward } \\
\text { Current } \\
\text { MAFC }\end{array}$ & $\begin{array}{c}\text { Capacitance } \\
\text { C }_{\mathrm{D}} @ \\
0.2 \text { Vrev,pk } \\
\text { (pF) }\end{array}$ \\
\hline NSR10F40NXT5G & 40 & 1 & 45 \\
\hline NXP PMEG4010EP & 40 & 1 & 50 \\
\hline NXP PMEG4020EP & 40 & 2 & 100 \\
\hline VISHAY SS16 & 60 & 1 & 47 \\
\hline VISHAY MSS1P6 & 60 & 1 & 27 \\
\hline MCC MBRX160 & 60 & 1 & 12 \\
\hline NXP PMEG6020ER & 60 & 2 & 76 \\
\hline NXP PMEG6020EPA & 60 & 2 & 80 \\
\hline NXP PMEG6030EP & 60 & 3 & 105 \\
\hline VISHAY SS3P6L & 60 & 3 & 110 \\
\hline VISHAY B360B & 60 & 3 & 130 \\
\hline Fairchild S100 & 100 & 1 & 52 \\
\hline ST STPS1H100A & 100 & 1 & 28 \\
\hline VISHAY 10MQ100 & 100 & 2 & 17 \\
\hline
\end{tabular}

TABLE IV. THE PARAMETERS OF THE SEVEN RECTIFIERS BUILT TO TEST THE DIODES AT $30 \mathrm{MHz}$. THE RECTIFIERS WERE OPERATED AT A DC OUTPUT VOLTAGE OF 0.2 TIMES THE PEAK DIODE VOLTAGE RATING

\begin{tabular}{|c|c|c|c|c|}
\hline Diode Group & $\begin{array}{c}\mathbf{C r}(\mathbf{p F}) \\
(\mathbf{C n}=\mathbf{0 . 3})\end{array}$ & $\begin{array}{c}\mathbf{L r}(\mathbf{n H}) \\
(\mathbf{L n}=\mathbf{2 . 0})\end{array}$ & $\begin{array}{c}\mathbf{C s} \\
\mathbf{( p F})\end{array}$ & $\begin{array}{c}\mathbf{L s} \\
(\mathbf{n H})\end{array}$ \\
\hline$\{40 \mathrm{~V}, 1 \mathrm{~A}\}$ & 199 & 84.8 & 74.4 & 378 \\
\hline$\{40 \mathrm{~V}, 2 \mathrm{~A}\}$ & 398 & 42.4 & 91 & 307 \\
\hline$\{60 \mathrm{~V}, 1 \mathrm{~A}\}$ & 132.6 & 127.3 & 50.5 & 557 \\
\hline$\{60 \mathrm{~V}, 2 \mathrm{~A}\}$ & 266 & 63.6 & 91 & 307 \\
\hline$\{60 \mathrm{~V}, 3 \mathrm{~A}\}$ & 398 & 42.4 & 91 & 307 \\
\hline$\{100 \mathrm{~V}, 1 \mathrm{~A}\}$ & 80 & 212.1 & 44.6 & 631 \\
\hline$\{100 \mathrm{~V}, 2 \mathrm{~A}\}$ & 160 & 106.1 & 57 & 493 \\
\hline
\end{tabular}

current to avoid the destruction of the diode: $i$ ) the temperature of the anode copper trace rises above $90^{\circ} \mathrm{C}$, and ii) the peak voltage of the diode rises above its rated value. These constraints are imposed to emulate a real application where the diodes are not driven at extreme conditions. Due to these constraints some diodes could not be utilized near their datasheet rated current. Some of these diodes are simply unfit for resonant rectification at VHF frequencies, while others can be derated and considered useful for operation at a fraction of their nominal (datasheet) rated current.

Figure 15 (a) shows the test results for the $40 \mathrm{~V}$ diodes. The PMEG4010EP is the diode with the lowest loss. In Fig. 15 (b) the PMEG6020ER and PMEG6020EPA have the least losses. Both are rated for $2 \mathrm{~A}$ but operate as $1 \mathrm{~A}$ devices in this particular test. Note that one of the diodes could not reach full current and this was due to exceeding temperature limits. Figure 15 (c) shows the $60 \mathrm{~V}, 2$ A test, of which only one diode could be used at full current. The diode with the best performance was the PMEG6030EP, de-rated to $2 \mathrm{~A}$. On the $60 \mathrm{~V}, 3$ A test, Fig. 15 (d), the PMEG6030EP performed the best. None of the diodes could reach rated current. Finally, the $100 \mathrm{~V}, 1-2$ A test is shown in Fig. 15 (e). Here the diode with least losses is the $\mathrm{S} 100$, but it was heavily de-rated because of high diode voltage stress. It is important to highlight that the capacitance $\mathrm{C}_{\mathrm{r}}$ of the $100 \mathrm{~V}$-diode rectifier is comparable in magnitude to the device capacitance as can be seen in Tables III and IV. The resonant capacitance is dominated by the nonlinear diode capacitance and, as shown in Fig. 12, this leads to higher voltage stress than predicted.

Three diodes with superior performance were chosen and tested in $50 \mathrm{MHz}$ rectifiers. The diodes are the PMEG4010EP $(I o=1 \mathrm{~A})$, PMEG6020ER $(I o=1 \mathrm{~A})$ and PMEG6030EP $(I o=$ $2 \mathrm{~A})$. The rectifiers were designed with the same specifications stated above with the exception of an increase in frequency to $50 \mathrm{MHz}$. Table V shows the rectifier parameters and Fig. 16 shows the test results. The power dissipation is slightly higher when operating at $50 \mathrm{MHz}$ but these three diodes are still useful in rectification at VHF frequencies. As frequency increases, the value of $\mathrm{C}_{\mathrm{r}}$ decreases and approaches that of $\mathrm{C}_{\mathrm{D}}$, the diode capacitance. In order to keep increasing operating frequency while maintaining resistive behavior, it is important to use diodes with low intrinsic capacitance.

\section{CONCLUSION}

A methodology for designing resonant rectifiers with nearresistive input impedance has been presented in this paper. We develop analytical expressions to model the rectifier, and provide a graphical approach for the design. The methodology is experimentally validated, and its limitations discussed. Various commercially-available Si Schottky diodes have been tested for their performance in class E resonant rectifiers at VHF frequencies. It is hoped that this design approach, the insights available from the design curves and the experimental evaluation of commercial diodes for VHF rectifiers will prove to be useful in designing resonant rectifiers. 


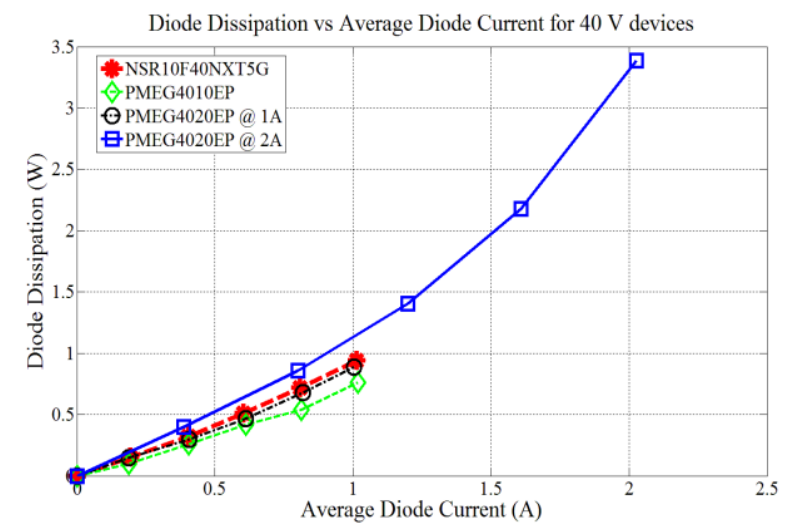

(a)

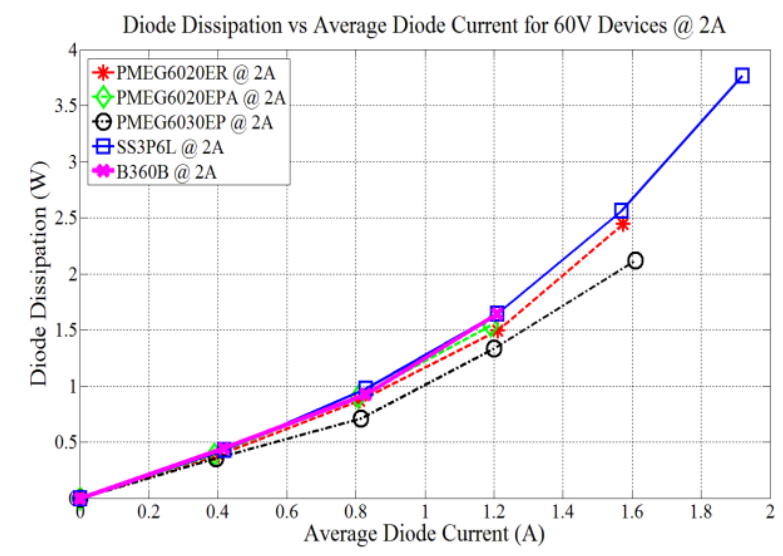

(c)

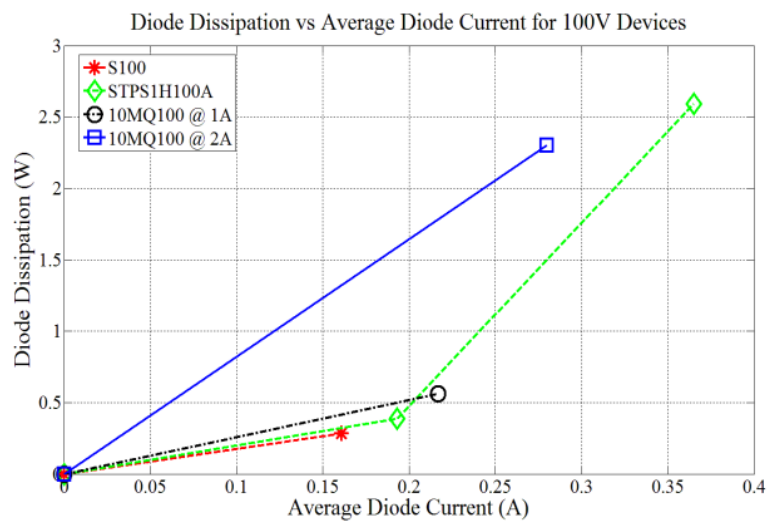

(e)

Figure 15. Diode testing results at $30 \mathrm{MHz}$. Diode dissipation vs. average current for class $E$ rectification into a dc output voltage of 0.2 times the diode rated voltage. The parameters of the rectifiers are listed in Table IV. From top to bottom, left to right: (a) $40 \mathrm{~V}, 1$ $2 \mathrm{~A}$; (b) $60 \mathrm{~V}, 1 \mathrm{~A}$, (c) $2 \mathrm{~A}$, and (d) $3 \mathrm{~A}$; and (e) $100 \mathrm{~V}, 1-2 \mathrm{~A}$.

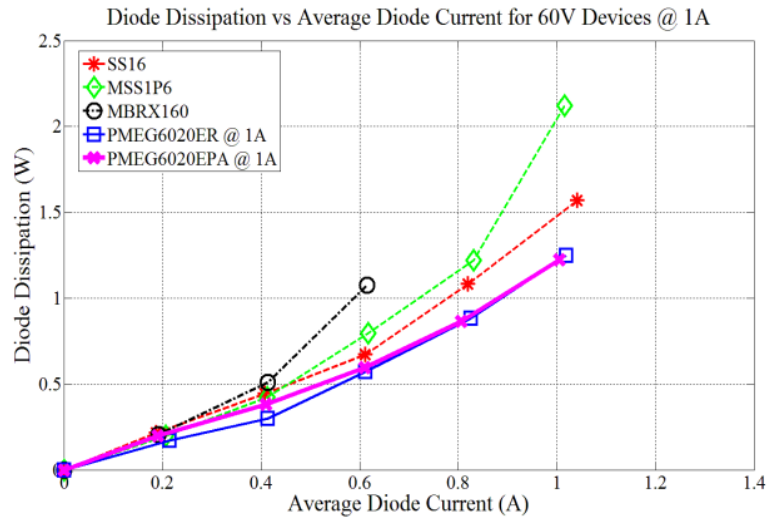

(b)

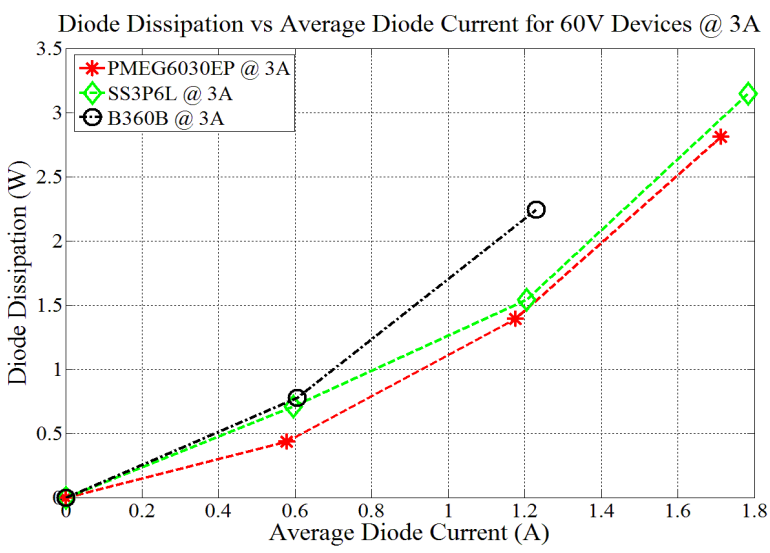

(d)

TABLE V. THE PARAMETERS OF THE RECTIFIERS BUILT TO TEST THE DIODES AT $50 \mathrm{MHZ}$. THE RECTIFIERS WERE OPERATED AT A DC OUTPUT VOLTAGE OF 0.2 TIMES THE PEAK DIODE VOLTAGE RATING.

\begin{tabular}{|c|c|c|c|c|}
\hline Diode Under Test & $\begin{array}{c}\mathbf{C r}(\mathbf{p F}) \\
\mathbf{( C n = 0 . 3 )}\end{array}$ & $\begin{array}{c}\mathbf{L r}(\mathbf{n H}) \\
\mathbf{( L n = 2 . 0 )}\end{array}$ & $\begin{array}{c}\mathbf{C s} \\
\mathbf{( \mathbf { p F } )}\end{array}$ & $\begin{array}{c}\mathbf{L s} \\
\mathbf{( n H})\end{array}$ \\
\hline PMEG4010EP & 119 & 47 & 47 & 222 \\
\hline PMEG6020ER & 80 & 82 & 27 & 334 \\
\hline PMEG6030EP & 160 & 39 & 47 & 206 \\
\hline
\end{tabular}




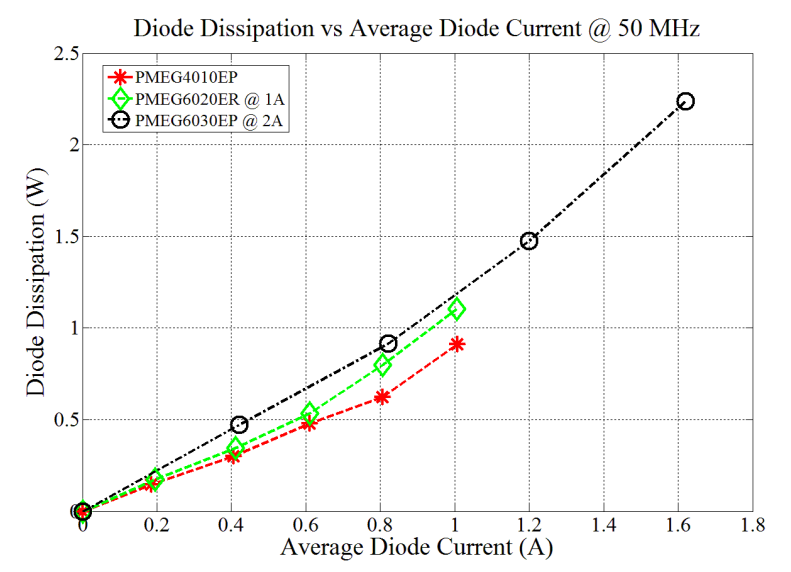

Figure 16. Diode testing results at $50 \mathrm{MHz}$. Diode dissipation vs. average diode current for class $\mathrm{E}$ resonant rectification into a dc output voltage of 0.2 times the diode rated voltage. The parameters of the rectifiers are listed in Table V.

\section{ACKNOWLEDGEMENT}

The authors would like to gratefully acknowledge the support provided for this research by an MIT-SkTech Strategic Development Project, the MIT Center for Integrated Circuits and Systems and the MIT/MTL GaN Energy Initiative.

\section{REFERENCES}

[1] J. Hu, A.D. Sagneri, J.M. Rivas, Y. Han, S.M. Davis, and D.J. Perreault, "HighFrequency Resonant SEPIC Converter with Wide Input and Output Voltage Ranges," IEEE Transactions on Power Electronics, vol. 27, no. 1, pp. 189-200, January 2012

[2] J.M. Rivas, O. Leitermann, Y. Han, and D.J. Perreault, "A Very High Frequency dc-dc Converter Based on a Class Phi-2 Resonant Inverter," IEEE Transactions on Power Electronics, vol. 26, no. 10, pp. 2980-2992, October 2011.

[3] W.A. Nitz, W.C. Bowman, F.T. Dickens, F.M. Magalhaes, W. Strauss, W.B. Suiter and N.G. Zeisse, "A New Family of Resonant Rectifier Circuits for HighFrequency dc-dc Conversion Applications," Proceedings of the IEEE Applied Power Electronics Conference (APEC), pp. 12-22, New Orleans, LA, February 1988.

[4] R.J. Gutmann and J.M. Borrego, "Power Combining in an Array of Microwave Power Rectifiers," IEEE Transactions on Microwave Theory and Techniques, vol. MTT-27, no. 12, pp. 958-968, December 1979.

[5] P. Godoy, D. J. Perreault, and J. L. Dawson, "Outphasing energy recovery amplifier with resistance compression for improve efficiency," IEEE Transactions on Microwave Theory and Techniques, vol. 57, no. 12, pp. 2895-2906, December 2009.

[6] C.-W. Chang, Y.-J. Chen, and J.-H. Chen, "A Power-Recycling Technique for Improving Power Amplifier Efficiency Under Load Mismatch," IEEE Microwave and Wireless Component Letters, vol. 21, no. 10, pp. 571-573, October 2011.

[7] Y. Han, O. Leitermann, D.A. Jackson, J.M. Rivas, and D.J. Perreault, "Resistance Compression Networks for Radio-Frequency Power Conversion," IEEE Transactions on Power Electronics, vol. 22, no.1, pp. 41-53, January 2007.

[8] W. Inam, K.K. Afridi and D.J. Perreault, "High Efficiency Resonant DC/DC Converter Utilizing a Resistance Compression Network," Proceedings of the IEEE Applied Power Electronics Conference and Exposition (APEC), Long Beach, CA, March 2013

[9] T.W. Barton, J.M. Gordonson, and D.J. Perreault, "Transmission Line Resistance Compression Networks for Microwave Rectifiers," 2014 International Microwave Symposium, June 2014.

[10] T.W. Barton, J.M. Gordonson, and D.J. Perreault, "Transmission Line Resistance Compression Networks and Applications to Wireless Power Transfer," IEEE Journal of Emerging and Selected Topics in Power Electronics, (Early Access 2014).

[11] M.K. Kazimierczuk, "Analysis of Class E Zero-Voltage-Switching Rectifier," IEEE Transactions on Circuits and Systems, vol.37, no.6, pp.747-755, June 1990.
[12] A.D. Sagneri, "Design of Miniaturized Radio-Frequency DC-DC Power Converters," PhD Thesis, Dept. of Electrical Engineering and Computer Science, Massachusetts Institute of Technology, Cambridge,MA,February 2012, Chapter 4.

[13] M.K. Kazimierczuk and J. Jóźwik, "Class E Zero-Voltage-Switching and ZeroCurrent-Switching Rectifiers," IEEE Transactions on Circuits and Systems, vol.37, no.3, pp.436-444, March 1990

[14] M.K. Kazimierczuk and K. Puczko, "Class E Low dv/dt Synchronous Rectifier with Controlled Duty Ratio and Output Voltage," IEEE Transactions on Circuits and Systems, vol.38, no.10, pp.1165-1172, October 1991.

[15] A. Ivaşcu, M.K. Kazimierczuk, and Ş. Birca-Galateanu, "Class E Resonant Low dv/dt Rectifier," IEEE Transactions on Circuits and Systems, vol. 39, no. 8, pp. 604-613, August 1992.

[16] I. Boonyaroonate and S. Mori, "Analysis and Design of Class E Isolated DC/DC Converter Using Class E Low dv/dt PWM Synchronous Rectifier," IEEE Transactions on Power Electronics, vol. 16, no. 4, July 2001.

[17] D.C. Hamill, "Class DE Inverters and Rectifiers for DC-DC Conversion," IEEE Power Electronics Specialist Conference, vol. 1, pp. 854-860, June 1996.

[18] Ş. Bîrcă-Gălăţeanu and J.-L. Cocquerelle, "Class E Half-Wave Low dv/dt Rectifier Operating in a Range of Frequencies Around Resonance," IEEE Transactions on Circuits and Systems, vol. 42, no. 2, pp. 83-94, February 1995.

[19] K. Sakuma and H. Koizumi, "Influence of Junction Capacitance of Switching Devices on Class E Rectifier," Proceedings from IEEE International Symposium on Circuits and Systems, pp. 1965-1968, Taipei, May 2009.

[20] R. Marante, M. Nieves Ruiz, L. Rizo, L. Cabria, and J.A. García, "A UHF Class E DC/DC Converter using GaN HEMTs," Proceedings from IEEE Microwave Symposium Digest (MTT), pp.1-3, Montreal, QC, Canada, June 2012.

[21] H. Koizumi, M. Iwadare, and S. Mori, "Class $E^{2} \mathrm{dc} / \mathrm{dc}$ Converter with Second Harmonic Resonant Class E Inverter and Class E Rectifier," Proceedings from IEEE Applied Power Electronics Conference and Exposition (APEC), pp. 10121018, Orlando, FL, February 1994.

[22] J.A. Santiago-Gonzalez, K.K. Afridi, and D.J. Perreault, "Design of resistive-input class E resonant rectifiers for variable-power operation," Proceedings from IEEE Control and Modeling for Power Electronics (COMPEL), pp. 1-6, Salt Lake City, UT, June 2013.

[23] L.C. Raymond, W. Liang, J.M. Rivas-Davila, "Performance Evaluation of Diodes in 27.12 MHz Class-D Resonant Rectifiers Under High Voltage and High Slew Rate Conditions," 2014 Workshop on Computers and Modeling in Power Electroniocs (COMPEL 2014), June 2014. 